Kohl: a Journal for Body and Gender Research

Vol. 5, No. 2 (Summer 2019)

\title{
On the Depoliticization of the Economy and Activism: Notes from a feminist fresh graduate on alienation and cooptation
}

\author{
Farah Baba
}


Women and feminist activists have been voicing their disapproval of the ways that oppositional politics have been framed and put to use by men in activist circles in various parts of the world. Students in Lebanon have been trying to reproduce the successful experiences of the past, namely the strikes and protests demanding affordable public education, while worrying about their futures under the current economy if their activism does not lead to swift and radical change. This work is often pushed into depoliticization and cooptation, which we have discussed and debated for years to no avail as part of our involvement in student and youth groups, and feminist circles. Today, feminism is labeled "trendy" or mainstream at best and "cliché" at worst. While writing this, I am overtaken by the feeling that everything has already been said, that my story is the same as that of other women and students. When our efforts and language are hijacked and appropriated, we bend in a way that is reminiscent of every worker's feeling when they are promised improvements in their work conditions. With the force and pressure exerted on us, our inner monologues often urge us to just be satisfied, to not get ourselves at risk for speaking or expressing dissent.

I examine the commonalities in the struggles I am part of as a woman, a feminist, and a fresh graduate. I analyze how these diverse experiences shaped the understanding of politics I share with others who, like me, have been involved at the intersections of students' and women's movements. To that end, I focus on exploring how these positionalities in turn shape the demands of women involved in oppositional politics under the economic structure of Lebanon. The country is currently undergoing many changes on the social, economic, and political levels. Protests against the deteriorating socio-economic conditions erupted at the beginning of the year as the prices of products, mainly gas, went up, and it became even more difficult for people to afford private education. More recently, the protests were directed against the austerity measures that were announced by the government and that hinted at the intentions to implement cuts in the wages of public sector employees, as well as cuts in the funding of the only public university (the Lebanese University). Well-attended and significantly covered on social media, these protests have been mostly organized and/or called for by the so-called "opposition," which includes a number of non-governmental organizations and civic movements. ${ }^{1}$ However, some other groups have voiced their skepticism over the public demonstrations for various political and organizational reasons.

From that end, I focus on how the current system and its opposition live off of coopting our different causes and struggles, and rebrand them in an attempt to appeal to what they assume to be a liberalized nonsectarian youth. I discuss how women and unimpressed students are being silenced and denied resources to organize politically, and why we always find ourselves isolated by efforts that erase our discontent. Finally, I compare the state and the so-called opposition, and discuss how the two share more similarities than differences.

\footnotetext{
1 Joumana Talhouk explains the vagueness of the term "civil society" in the Lebanese context, in her article on "Parliamentary Elections, Civil Society, and Barriers to Political Change," published in Kohl: a Journal for Body and Gender Research, Vol. 4 No. 1 (2018): pp. 23-29. https://kohljournal.press/parliamentary-elections
} 


\section{As Women in the Patriarchal Status Quo}

In the few youth groups I was part of and the meetings I have attended in the past three years, women's engagement in political groups is often dismissed as invisible labor: we are branded by the men counterparts as idealistic and not realistic enough, and our understanding of the actual situation and what it entails is deemed lacking. When we get angry, they tell us to drop our "aggressive" discourse and to be grateful, because we have it better than the women before us who struggled and suffered so that we, the women of this age and time, have the chance to be on the meeting table. In other words, the history of our cause is used against us, and our presence in the meeting is portrayed as privilege in and of itself.

The condescending but nonetheless seemingly friendly "advice" tells us to leave our woman identity outside the meeting room. Furthermore, we are told to leave our plights behind, when sexual harassment occurs, in favor of the male perpetrator, especially when he has good economic stances and a guaranteed position in organizing. The group finds him indispensable and refuses to abandon him for a "one-time incident." "Nobody is perfect and now is not the time to call out harassment; we're busy plotting a revolution," is an excuse heard too often. However, when it comes to feminist demands, they are met with plain ridicule and depoliticization, as they are reduced to individual struggles unworthy of immediate attention. Our concerns are "not prioritized at the moment" and "now is not a good time" to voice our discontent. And the result is that we leave and they stay. Our spaces of resistance start to shrink and we may end up in a constant loop of efforts to seek and create new safe spaces and enter new groups. This is one of the criticisms I encounter mostly in social media "jokes," but also in occasional discussion about feminism in Beirut: feminists jump in-between temporary spaces all the time; they are not reliable. But why is this small act of resistance dismissed in favor of condoning the sidelining we face and the harassment we fear?

The silencing of our demands and cooptation of our cause is systematic to the extent that it makes us question whether we are really oppressed in this context. Not only does it damage our organizing efforts, but it also harms our belief system. We end up leaving the spaces of organizing and leaving resources to those who originally had them, with no mechanisms of accountability in place to give us justice. As stressed by Hiba Abbani (2012) while reflecting on the Left and women in Lebanon, no revolutionary demands or temporary struggles are more important than others. ${ }^{2}$

\section{As Students in a For-Profit Educational System and a Capitalistic Job Market}

Neoliberal policies shaped the Lebanese economy after the civil war; they have caused a strong dominance of the non-profit sector following the extensive focus on economic development to serve a certain social class. Today's education in private universities and schools is very expensive, and the students have little to no say in what they are taught. In turn, these institutions play a significant role in reinforcing neoliberal ideals. In a class on psychological disorders, for example, we learned that the main symptom of being

\footnotetext{
${ }^{2}$ https://www.al-manshour.org/node/7911
} 
psychologically unwell is the absence of productivity and the disengagement or isolation from work and studies. We were also taught that there are treatments to reintegrate the unproductive back into society. How else can someone make meaning of their life if they are not contributing to the existing economy?

Similarly, private universities nowadays are investing too much of their time and resources on promoting "social entrepreneurship" as a solution to social problems. They are training their students on being active citizens and "agents of change." It fosters the culture of individuality and self-gratification: one can invest in their "potential" by founding a startup to tell the world that they care about social problems and to come up with "innovative" ways to resolve them. The profit-oriented marketing strategies guised as creative genuine efforts generate profit from a business model, all the while neglecting the political roots of the problems it claims to solve. Take the example of the multiple startups promoted by universities that are participating in the ideathons and hackathons: they claim to tackle youth unemployment, but never address the unfair distribution of resources and wealth or the clientelist nature of the economy. Student and youth movements in the past were very different: in the 1950s, private university students demanded affordable and quality public education. Today, student activism is replaced with social entrepreneurship. When we do try to organize, we are faced with a wrongful prioritization of demands guised as a reality check to focus solely on the issues that directly affect the youth and students such as tuitions, the job market and so on, and we are told to drop the political demands because others have been trying and failing. Some student and youth groups even refuse to identify as political in any sense and insist on playing a purely syndical role. This leads to the marginalization of crucial demands in relation to women and sexual minorities' rights, freedom of political activity and expression, and even the economy's role in students' daily struggles such as tuition fees and job opportunities, loans, and debts.

Perusing a career in the humanitarian or non-profit institutions becomes among the very few choices we have after graduating with degrees in social sciences and humanities. But what alternative career and academic paths are left for us under such an economic model? We learn and believe that it is completely hopeless and unrealistic - to achieve any change through state institutions in the absolute sense. Hence we have very few spaces afforded to our "age range" and political values. Neither does my criticism deem us hypocrites for working against our politics, nor is it pointed to NGOization alone. Rather, it concerns itself with the overall systematic limitations that force us to go into these fields and to abide by certain guidelines that, more often than not, we are not satisfied with at all.

\section{As Activists against the Mainstreaming of Causes}

Linking economic demands to social plights exposes the systematic nature of the problems we face and their structural sources. However, the new wave of political participation and activism stems from NGOs, hence presenting people of this sector as the pioneers at the forefront of the "opposition" in the political battles. This self-assigned image is contrasting with the actual advocacy role that the NGOs usually play. Furthermore, they fail to address or even describe the system as is, instead choosing to focus on void empowerment 
campaigns whose target audience we cannot identify. NGOization diverts from the structural problems we face and calls for reforms, completely neglecting the structural sources lying behind all of the issues.

From my brief involvement with Mist3ideen, a group that emerged during the elections season to interview all the independent candidates and evaluate them based on a set of political values and principles, ${ }^{3}$ the civil society's participation in the parliamentary elections a year ago exemplifies such trends. It lacked a coherent and progressive discourse and demands, as member groups had contradicting values and goals. It was dominated by a "patriotic" discourse adopting the de facto exclusion of non-Lebanese residents suffering from the same system. Perhaps most importantly, it promoted the participation of non-governmental organizations' leaders as recognizable "faces" in the "opposition" campaign, rather than and at the expense of politicized candidates with clear electoral platforms.

We can argue that this is a form of cooptation of political struggles, efforts, and organizing in the sense that our economic system basically renders our causes "marketable" and "shareable" through likeable social media campaigns and simplistic slogans and rhetoric. The political essence is taken out of the political issue by the establishment, the NGOs, as well as the groups who push for political participation and civic engagement. For instance, the recent gender mainstreaming efforts on gender-based violence included a very brief definition of the notion of gender and completely disregarded the power dynamics and sexual politics behind the struggle. Instead, these campaigns and efforts by the self-proclaimed feminist NGOs focus solely on recognized institutions such as family members, inter-partner violence etc., diluting the greater context. They only tackled gendered violence from the starting point of humanitarian assistance. Perhaps the failures to critically address such issues are linked to the organizations' financial dependence on the donors, and thus to the obligation to abide by their agendas. This form of advocacy and activism gains more visibility and recognition in the public realm than the efforts of the political groups trying to organize. Social issues are not addressed systematically due to the state's minimalist administrative role, which leaves service provision to the private and non-profit sectors. These short-term campaigns pay our bills at the end of the month but do not constitute structural change.

Thus, yet again, we are alienated, questioning our politics and ways of organizing, at times resorting to the pure pragmatism of choosing "the lesser evil" and the faster route.

The establishment, capitalist and patriarchal, appropriates our discourse and dilutes it. Over the years, we've lost track of the number of times we've heard pillars of the sectarian system promoting the "civil state" as the solution to the failure of the country. And what is perhaps more ironic is that we're recently hearing the pillars of the failed economic model call for social justice. What, then, is left of our discourse to share with the public?

${ }^{3}$ https://mist3ideen.com/criterial 
Every time we voice this criticism, opposition groups fail to address it. They reinforce and reproduce a classist discourse that describes people as brainwashed sectarian "sheep" who are to blame for the status quo. They call for remedies such as elections. However, these are inherently classist and naïve, as they wrongly assume that politics in Lebanon happen at the institutional level. They consider people making the same choices over and over again an individual failure, failing to explore the socioeconomic conditions and classist undertones of such placement of blame. ${ }^{4}$ This simplistic understanding robs people of their agency and autonomy, further exacerbating the austerity measures the government is undertaking. These measures would potentially fuel a divide between the workers of the private sector and those of the public sectors, seen as rivals. It alienates us again from our hope of uniting "workers against the establishment."

So how do we move forward from here? How do we resist this cooptation and keep fighting for our causes using the resources we have without worrying about being labelled aggressive? I believe that by constantly asking us to calm down and tame our anger, segments of the opposition are attempting to sugarcoat reality and delegitimize our work on the basis of anger being an emotion - and emotions "have no place in successful oppositional politics." We are not being "too radical" or exclusionary when we refuse to market our causes and beautify them for the public gaze. Ideological differences are a deal breaker and change is only achieved when we direct this criticism both inwardly and outwardly, against the establishment and within our organizing.

${ }^{4}$ Rima Majed, "Why the Lebanese Support the Same Sectarian Leaders," published on Aljazeera on April 6, 2017. https://www.aljazeera.com/indepth/features/2017/03/lebanese-support-sectarian-leaders-170312084011811.html 